DOI 10.37882/2223-2982.2021.11-2.24

\title{
ОСОБЕННОСТИ ФОРМИРОВАНИЯ ГОТОВНОСТИ БУДУЩИХ МЕНЕДЖЕРОВ К ПРОФЕССИОНАЛЬНОЙ ДЕЯТЕЛЬНОСТИ
}

\section{FEATURES OF FORMING THE READINESS OF FUTURE MANAGERS FOR PROFESSIONAL ACTIVITIES}

\author{
T. Pankova \\ Z. Abdullayeva \\ V. Goncharova \\ T. Galeeva \\ E. Yanova
}

Summary: The quality of professional training of future managers is of great importance in addressing the issues of improving the quality and efficiency of management, the development and implementation of new management technologies. This article discusses the problem of forming the readiness of future managers for professional activities in the process of training in higher education institutions, which is becoming increasingly important, since the effectiveness of the future development of Russian society largely depends on its successful solution.

Keywords: manager, readiness, readiness for professional activity, readiness of the future manager for professional activity, professional training.
Панкова Татьяна Николаевна

К.филол.н., дочент, Воронежский государственный университет

pankovatn30@mail.ru

Абдуллаева Зульфия Рагим кызы

Старший преподаватель, Московский институт

стали и сплавов

zulya5596@gmail.com

Гончарова Валерия Владимировна

К.п.н., дочент, РЭУ им Г.В. Плеханова (Москва)

Goncharova.VV@rea.ru

Галеева Татьяна Ильинична

К.фр.н., доцент, Московский международный университет tilisait@gmail.com

Янова Елена Александровна

Старший преподаватель, Московский международный университет stonel@rambler.ru

Аннотация: Большое значение в решении вопросов повышения качества и эффективности управления, разработки и внедрения новых управленческих технологий приобретает качество профессиональной подготовки будущих менеджеров. В данной статье рассмотрена проблема формирования готовности будущих менеджеров к профессиональной деятельности в процессе обучение в учреждениях высшего образования, которая приобретает значительную актуальность, поскольку от ее успешного решения во многом зависит эффективность будущего развития российского общества.

Ключевые слова: менеджер, готовность, готовность к профессиональной деятельности, готовность будущего менеджера к профессиональной деятельности, профессиональная подготовка.

ростом требований со стороны общества к повышению эффективности управленческой деятельности [11].

Из этого следует, что одной из приоритетных задач подготовки будущих менеджеров к профессиональной деятельности в процессе обучения в учреждениях высшего образования является формирование их готовности к профессиональной деятельности [13]. Именно в процессе подготовки к профессиональной деятельности у будущих специалистов формируются навыки эффективной работы в среде динамично меняется, желание совершенствовать и развивать собственный управленческий потенциал, и не только [7, с. 202].

Анализ проблемы формирования готовности будущих менеджеров к профессиональной деятельности в современной педагогической теории и практике предусматривает рассмотрение основных подходов к изучению сущности понятий «менеджмент» и «Менеджер», 
особенностей профессиональной деятельности современного менеджера, а также возможностей управленческой деятельности и менеджмент-образования.

Интерес к проблеме менеджмента обусловлен изменениями в системе и методах управления во всем мире и повышением требований, предъявляемых к менеджерам и их профессионализму, а также модернизацией системы оценивания [12, с. 31]. Понятие «менеджмент» происходит от английского слова «to manage», которое означает «управлять, управлять, стоять во главе, заведовать, быть способным справиться с любой проблемой «. Фундаментальный Оксфордский словарь английского языка определяет менеджмент как способ, манеру общения с людьми, власть и искусство отношений, особого рода умения и административные навыки, орган управления [3]. Итак, менеджмент является совокупностью принципов, функций, методов, средств управления, обеспечивающих упорядоченность всех внутренних процессов организации и эффективность ее деятельности.

Особая роль в подготовке будущих менеджеров отводится образованию, направления которого отражены в государственной концепции его модернизации и связанные с возрастанием роли лидерского потенциала, раскрытием потенциальных возможностей личности. Современная высшая школа должна помочь каждому студенту в определении себя как ответственной, свободной в своем творческом выборе, активной и инициативной личности. В связи с этим остро встает проблема поиска, подбора и профессиональной подготовки наиболее способной, талантливой молодежи. Именно в студенческие годы наиболее полно раскрываются организаторские склонности, формируются и развиваются умения и навыки лидера, необходимые для эффективного руководства коллективом. Будущие менеджеры должны представлять значимость лидерства и лидерского потенциала для успешной профессиональной деятельности.

Итак, менеджмент-образование в России предлагает различные образовательно-профессиональные программы подготовки будущих менеджеров, качество которых не соответствует запросам общества по подготовке управленцев, а западный опыт часто реализуется на уровне внешних атрибутов без анализа его сущностных характеристик. Происходит, по сути, «копирования» образцов деятельности и готовых теоретических знаний, оторванных от реальной управленческой практики. Становится очевидным тот факт, что подготовка менеджеров в учреждениях высшего образования должна быть переведена на качественно новый уровень. Она требует эффективного педагогического сопровождения процесса формирование готовности будущих менеджеров к профессиональной деятельности, что, в свою очередь, является решающим фактором успешности функциони- рования организации, государства и общества в целом.

Формированию готовности будущих менеджеров к профессиональной деятельности способствует самостоятельная работа студентов, в исполнении которой следует выделить два уровня: управляемая преподавателем аудиторная и внеаудиторная самостоятельная работа студентов, и самостоятельная работа по самообразованию и самовоспитания, которая осуществляется по своевременной инициативе студентов. Первый уровень предусматривает увеличение роли самостоятельной работы студентов в процессе аудиторной и внеаудиторной занятия для того, чтобы они научились осмысленно и самостоятельно работать сначала с учебным материалом, затем - с научной информацией. Реализация этого пути требует от преподавателей разработки методик и форм ее организации, способных обеспечить высокий уровень самостоятельности студентов и улучшение качества их подготовки. Второй уровень заключается в том, что в результате самостоятельной работы, которая выполняется студентами по собственной инициативе на основе самообразования и самовоспитания, они осуществляют саморазвитие умение непрерывно повышать свою квалификацию. Роль преподавателя сводится к предоставлению консультативной помощи и стимулирования этого процесса.

На сегодняшний день постоянно растет роль педагогических и психологических знаний, что обусловлено усилением роли человеческого фактора, необходимостью создания эффективных условий для развития и саморазвития потенциала будущих менеджеров. В связи с указанным считаем необходимым: обеспечивать формирование профессионально важных качеств, лидерских и других качеств, эмоционального интеллекта, коммуникативных и организаторских склонностей, важных для успешной управленческой деятельности; активизировать и разнообразить самостоятельную работу в процессе обучения и направлять деятельность студентов на самосовершенствования путем самоконтроля, саморегуляции и саморазвития. В связи с этим в процессе подготовки будущих менеджеров в соответствии со спецификой управленческой деятельности нужно особое внимание уделять формированию их педагогической и психологической готовности, активизации внутренних ресурсов личности. Анализ образовательно-профессиональных программ подготовки будущих менеджеров показал, что за последние годы количество учебных часов, отведенных на изучение курса психологии, было уменьшено.

В современных условиях подготовка будущих менеджеров в учреждениях высшего образования должна базироваться на процессах преобразования и адаптации к актуальным требованиям и национальным ожиданиям в условиях трансформации всей системы образования, и умении действовать в изменяющихся условиях. Она 
должна гарантировать будущим менеджерам приобретение профессиональных знаний в области организации и управления, экономики, финансов, маркетинга, информатики, владение математическими и компьютерными техниками, иностранными языками, также совокупностью гуманитарных знаний по психологии, педагогике, социологии и умение ими пользоваться.

Проблема формирования готовности будущих менеджеров к профессиональной деятельности существенно меняет роль и место педагога в этом процессе - от трансляции знаний и способов деятельности к проектированию индивидуальной траектории их интеллектуального и личностного развития. При этом преподаватель планирует задачи, на решение которых должны быть направлены усилия студентов, стимулирует их, а они принимают эти задачи и осуществляют запланированные действия, опираясь на помощь и поддержку преподавателя. Педагогическое сотрудничество преподавателей со студентами - это процесс их социально-психологического взаимодействия, направленный на обучение и воспитание с целью профессиональной подготовки высококвалифицированных специалистов. Только при таких условиях создаются благоприятные условия для развития профессиональной направленности студентов, личностного роста посредством формирования лидерского потенциала, профессионально важных качеств, эмоционального интеллекта, организаторских и коммуникативных компетенций, самосовершенствование путем самоконтроля, саморегуляции и саморазвитию и других компонентов готовности будущих менеджеров к успешной профессиональной деятельности.

Стиль сотрудничества - совокупность конкретных приемов и способов, которые преподаватель реализует в своей деятельности на основе личных знаний, профессионального опыта, способностей и умений, использование педагогических технологий в процессе обучения. Он обеспечивает максимальное совершенствование как собственного личностного и профессионального потенциала, так и активизацию индивидуальных способностей студентов. При этом авторитет преподавателя формируется на основе достаточно высокого уровня знаний как учебной дисциплины, которую он представляет, так и характеристик студентов и самого себя, умение корректировать собственное поведение.

Культура педагогического общения включает умение слушать, задавать вопросы, анализировать ответы, давать объяснения, выражать свое отношение к данному вопрос, понимать студента, сотрудничать с ним, создавать ситуации успеха. Это увеличивает веру молодого человека в свои силы и возможности, порождает надежду на достижения успеха в будущей профессиональной деятельности и способствует личностному росту студентов, повышению их активности и самореализации.
Особая роль в подготовке будущих менеджеров отводится образованию, направления которой отражены в государственной концепции ее модернизации и связанные с ростом роли лидерского потенциала, раскрытием потенциальных возможностей личности. Современная высшая школа должна помочь каждому студенту в определении себя как ответственной, свободной в своем творческом выборе, активной и инициативной личности. В связи с этим остро встает проблема поиска, подбора и профессиональной подготовки наиболее способной, талантливой молодежи. Именно в студенческие годы наиболее полно раскрываются организаторские склонности, формируются и развиваются умения и навыки лидера, необходимые для эффективного руководства коллективом. Будущие менеджеры должны представлять значимость лидерства и лидерского потенциала для успешной профессиональной деятельности. Необходима разработка и апробация целостной программы педагогической поддержки лидерских проявлений у студентов, основанной на положениях личностно ориентированного подхода во взаимодействии всех участников образовательного процесса, его методологическое и методическое обеспечение.

Известно, что учебно-познавательная деятельность людей является основным способом овладения знаниями. Одновременно она является необходимым условием, при котором будущий менеджер приобретает не только знаний, но и жизненного опыта, вырабатывает умение и навыки, развивает психические процессы, раскрывает и развивает свой потенциал, формирует интеллектуальные, личностные, эмоционально-волевые качества и способности. Преимущественное значение в познавательной деятельности имеет установление взаимосвязи между различными сферами исследуемой реальности, отдельными аспектами профессиональной деятельности, потребность в познании и самопознании, в саморазвитии и самосовершенствовании. При этом знания является условием мышления студента и основой его развития. Однако приобретенный в результате обучения объем знаний не всегда свидетельствует о положительных изменениях в умственном развитии человека. Часто студенты механически заучивают полный набор фактов, понятий, законов, не понимая их сути. Негативные тенденции в освоении и использовании знаний также наблюдаются, когда преобладают метод обучения на основе стандартных действий, когда присутствует некритичный подход к методологии научной дисциплины и формальное усвоение не всегда полного и необходимого объема полезной информации.

Готовность будущих менеджеров к профессиональной деятельности как целостный интегративный феномен имеет интегративно-развивающий характер. На процесс его формирования при обучении влияет разнообразные объективные дидактические факторы: орга- 
низационно-педагогическое пространство; содержание и объем учебного материала; способы и методы обучения. Этот процесс требует создания благоприятных педагогических условий. Педагогическая система может успешно функционировать и развиваться только при соблюдении определенных условий [5].

К специальным принципам формирования готовности будущего менеджера к профессиональной деятельности нами отнесены следующие принципы:

- Принцип диалогизации обучения определяет направленность процесса коммуникативного взаимодействия на решение задач формирования готовности будущего менеджера к профессиональной деятельности путем обмена смысловыми позиции-суждениями. Указанный принцип предполагает отказ преподавателя от монолога как способа статусного доминирование, субъектобъектных отношений со студентом, манипулирования, догматизма, стереотипности в трансляции знаний в пользу продуктивного социально ориентированного интерактивного общения - диалога. Реализуется с помощью лекции-дискуссии, лекции-диалога, эвристической беседы, круглого стола, метода анализа проблемных ситуаций, технологии групповой поисковой деятельности (синектики) и др.

- Принцип проблемности играет важную роль в стимулировании учебно-познавательной деятельности будущих менеджеров, активизации познавательных, профессионально ориентированных мотивов. Эффективность использования проблемности в реализации модели формирования готовности будущего менеджера к профессиональной деятельности обеспечивается использованием различных способов создания проблемных ситуаций: затруднения при объяснении отдельных фактов; анализ противоречивых фактов; сравнения, сопоставления фактов; выдвижение гипотез и их проверка.

- Принцип фасилитации. Фасилитация в педагогике и психологии рассматривается как стимулирующее, инициирующие, оказывающее влияние на саморазвитие, самовоспитание обучающегося [2]. Склоняемся к тому, что фасилитация способствует укреплению партнерской позиции преподавателя во взаимодействии со студентами, что является важным условием успешного процесса формирования готовности будущего менеджера к профессиональной деятельности в образовательном процессе.
- Принцип осознанной перспективы в процессе формирования готовности будущего менеджера к профессиональной деятельности требует глубокого понимания студентом близких, средних и дальних перспектив. Этот принцип обеспечивается созданием условий для осознания будущими менеджерами важности формирования готовности к профессиональной деятельности, а также возможностями совершенствования ее уровня в будущей перспективе. При реализации этого принципа студент должен осознавать программу собственной деятельности в рамках каждой дисциплины; дидактическую цель; значим для студента и ожидаемый результат; необходимость применения полученных знаний в будущей профессиональной деятельности; необходимость профессионального роста для достижения успеха в профессии. Реализация этого принципа предполагает: ознакомление будущих менеджеров в начале изучения каждой дисциплины образовательно-квалификационными требованиями к знаниям и умениям, а также с учебно-воспитательными целями указанных дисциплин, студент должен понять и осознать, как личностно значимый и ожидаемый результат; контроль входного уровня знаний; ознакомление будущих менеджеров с системой достижения результатов и оценки собственных знаний (выходной контроль).

Профессиональная деятельность современного менеджера имеет сложный и разнообразный характер, что в конечном итоге требует необходимости подготовки компетентного руководителя, обладающего профессиональными знаниями, умениями и навыками, современными информационными технологиями, основами науки управления, имеющего достаточную психологическую подготовку, а также способного действовать в постоянно меняющихся условиях. Целью практической подготовки должно быть формирование у студентов основ профессионального мастерства, а ее содержанием - реализация приобретенных знаний, умений и навыков объектов профессиональной деятельности в реальных, производственных условиях. Подытоживая, можно утверждать, что влияние реализованных педагогических условий формирования готовности будущих менеджеров к профессиональной деятельности в учебном процессе учреждения высшего образования и его научно-методического обеспечения является существенным фактором и значимым элементом повышения уровня сформированности готовности к профессиональной деятельности. 
фоломеева // Учёные записки Ульяновского государственного университета: Актуальные проблемы лингвистики и преподавания лингвистических дисциплин / Факультет лингвистики, межкультурных связей и профессиональной коммуникации Института международных отношений Ульяновского государственного университета. - Ульяновск: УлГУ, 2017. - С. 160-164.

2. Кричевский Р.Л. Психология лидерства: учеб, пособ. М.: Статут. 2007. 542 с.

3. Оксфордский толковый словарь по психологии. Под. ред. А. Ребера. М.: Наука, 2002. 435 с.

4. Пундик И.Я. Фасилитирующая функция педагогических технологий в деятельности преподавателя вуза. Ярославский педагогический вестник, 2009. №2(59). С. 119-124.

5. Сластенин В.А., Исаев И.Ф., Шиянов Е.Н. Педагогика: учеб, пособ. М.: Академия, 2002.576 с.

6. Тишанинов, И.А. Влияние современной музыки на психологическое состояние подростков / И.А. Тишанинов // Проблемы теории и практики современной психологии: материалы XX Всероссийской научно-практической конференции с международным участием, Иркутск, 23-24 апреля 2021 года. Иркутск: Издательство ИГУ, 2021. - С. 243-244.

7. Усов, С.С. Применение игровой формы в обучении иностранным языкам / С.С. Усов, М.А. Сафонов // Индустрия туризма: возможности, приоритеты, проблемы и перспективы. - 2020. - Т. 16. - № S1. - С. 202-207.

8. Федорова, А.В. Отражение пандемии коронавируса на образование неологизмов в итальянских СМИ / А.В. Федорова, В.А. Марциновская // Актуальные проблемы общей теории языка, перевода, межкультурной коммуникации и методики преподавания иностранных языков: Сборник статей по материалам межрегиональной научно-практической конференции, Москва, 15-16 января 2021 года. - Саранск, 2021. - С. 28-34.

9. Харченко, Н.Л. Основные аспекты преподавания иностранного языка студентам, обучающимся по специальности «гостиничное дело» / Н.Л. Харченко // Индустрия туризма: возможности, приоритеты, проблемы и перспективы. - 2020. - Т. 16. - № S1. - С. 217-222.

10. Харченко, Н.Л. Особенности цифровой трансформации образовательных процессов в условиях высшей школы / Н.Л. Харченко // Педагогическая информатика. - 2020. - № 4. - С. 202-207.

11. Project risk management in the construction of high-rise buildings / B. Titarenko, A. Hasnaoui, R. Titarenko, L. Buzuk // E3S Web of Conferences, Samara, 04-08 сентября 2017 года. - Samara: EDP Sciences, 2018. - P. 03074. - DOI 10.1051/e3sconf/20183303074.

12. Swot analysis of moodle platform application in the assessment of foreign language knowledge / S. Usov, M. Safonov, L. Sorokina, E. Akbilek // ACM International Conference Proceeding Series : 4, Virtual, Online, 19-22 июля 2020 года. - Virtual, Online, 2020. - P. 31-34. - D0I 10.1145/3416797.3416835.

13. Varfolomeeva, N.S. English for professional communication : Учебно-методическое пособие / N.S. Varfolomeeva, D.V. Semenov; Российский государственный социальный университет. - Москва: Российский государственный социальный университет, 2019. - 25 р.

( Панкова Татьяна Николаевна (pankovatn30@mail.ru), Абдуллаева Зульфия Рагим кызы (zulya5596@gmail.com), Гончарова Валерия Владимировна (Goncharova.WV@rea.ru), Галеева Татьяна Ильинична (tilisait@gmail.com), Янова Елена Александровна (tonel@rambler.ru).

Журнал «Современная наука: актуальные проблемы теории и практики» 